\title{
Fighting Girls: A Representatividade Feminina no Jogo Street Fighter V
}

Fighting Girls: Woman Representation in the Game Street Fighter V

ISHIKAWA, Gisele Baldo; Graduanda em Design Gráfico; UNESP - Universidade Estadual Paulista "Júlio de Mesquita Filho"

gi_baldo@hotmail.com

HENRIQUES, Fernanda; Professora Doutora; UNESP - Universidade Estadual Paulista "Júlio de Mesquita Filho"

ferdi@faac.unesp.br

\section{Resumo}

Este artigo tem como propósito dissertar a respeito da representatividade feminina dentro do universo dos games, mais especificamente do jogo Street Fighter V. Foi realizado um levantamento acerca da história dos videogames e da participação feminina com o intuito de compreender como as mulheres se encaixam dentro desse ambiente tanto como desenvolvedoras quanto como consumidoras. Além disso, são tratadas questões acerca da objetificação e hipersexualização de personagens femininas nos games.

Palavras Chave: videogame; representatividade feminina; hipersexualização.

\begin{abstract}
This article aims to make a study about the female representation in the universe of games, specifically Street Fighter $V$. To this was made a brief study about the history of video games and the female participation in it, trying to understand how women fit within that environment as both developer and consumer. In addition, questions are raised about the objectification and hypersexualization of female characters in games, focusing on the games.
\end{abstract}

Keywords: video game; woman representation; hypersexualization. 


\section{Introdução}

Ao se pensar em jogos de videogames é comum imaginar que esta é uma atividade exclusivamente masculina. Durante muitos anos os jogos de videogame foram pensados tendo como foco somente os jogadores do sexo masculino. Essa classificação de gênero se iniciou durante a década de 1980, período em que o mercado de games passou por uma crise e, para evitar riscos, as produtoras de jogos eletrônicos voltaram seus olhos para o público masculino, seu maior consumidor. Ainda que no passado fosse de fato majoritariamente masculino, pode-se observar uma mudança no cenário. Conforme apontam pesquisas realizadas pelo Internet Advertising Bureau (2014) e pela Pesquisa Game Brasil (2017), atualmente as mulheres são as maiores consumidoras de jogos eletrônicos tanto no cenário nacional quanto no mundial.

A crença de que videogames são "coisa para meninos" faz com que muitos dos jogos sejam projetados para agradar esse público. Por isso, é ainda comum encontrar jogos onde o protagonista é homem e deve ser o herói que irá salvar o dia ou a mocinha indefesa. Além disso, muitos jogos adicionam personagens femininas somente para agradar ao público masculino, e não para realmente representar a diversidade feminina. Essas mulheres costumam ser representadas com curvas surreais, nádegas e seios fartos, roupas que mostram boa parte da pele e que não estão adequadas às situações apresentadas no game.

Entretanto, muitas empresas já perceberam a necessidade de se fazer adequações a seus jogos: no ano de 2016 foram anunciados jogos com protagonistas femininas com corpos mais próximos da realidade, utilizando roupas que condizem com a situação enfrentadas por elas. Apesar disso, os jogos de luta ainda vão contra essa tendência. Boa parte deles ainda são voltados ao público masculino, por isso suas personagens são planejadas com características que agradam esse público e mantenha seus consumidores fiéis aos jogos. Por outra via, isso pode ser um fator que afaste o público feminino (que é o maior consumidor de videogames na atualidade) desse estilo de jogo por não se sentirem representadas pelas mulheres presentes ali.

\section{Método de Pesquisa}

Para a produção deste artigo, foram feitas pesquisas acerca da questão da objetificação e da representatividade feminina. A metodologia incluiu pesquisa bibliográfica, notadamente em artigos científicos que tratavam dos temas videogames e feminismo. Também foram consultados diversos sites sobre a história dos videogames para compreender melhor como esse tipo de mídia se desenvolveu e como se tornou uma atividade conhecida como sendo masculina. Foi realizada uma análise do objeto a partir do entendimento de representatividade feminina nos videogames a partir do recorte no jogo Street Fighter $V$. Também foram feitos estudos acerca de concept art e de design de personagens, buscando compreender como o processo de criação interfere na mensagem transmitida ao observador. Ademais, para entender qual o público consumidor do jogo, analisou-se a lista dos participantes do campeonato de jogos de luta Evolution Championship Series (EVO) para saber se existem mulheres competindo nele, visto que, atualmente, este tipo de campeonato tem feito muito sucesso entre os fãs de jogos de luta ${ }^{1}$, sendo Street Fighter o jogo com maior destaque, com suas finais encerrando o campeonato.

As características do público gamer brasileiro foram baseadas na Pesquisa Game Brasil de 2017, cuja versão gratuita estava disponibilizada em seu site. Através dessa pesquisa foi possível

\footnotetext{
${ }^{1}$ https://blog.saraiva.com.br/conheca-as-4-modalidades-de-esport-mais-populares-do-mundo/
} 
constatar que boa parte do público consumidor de jogos eletrônicos no Brasil é feminino. A pesquisa também aponta que os tipos de jogos preferidos por essas mulheres são estratégia e aventura. Ou seja, foi constatado que, pelo menos aqui no País, o público feminino não se interessa por jogos de luta.

Por fim, foi realizada uma análise do design de algumas das personagens da franquia com base na questão da objetificação e da representatividade feminina tendo como referência as artes oficiais e as animações de entrada e de vitória de cada personagem.

\section{Concept Art e Design}

O termo concept art diz respeito ao desenvolvimento visual ou à concepção de um conceito (NAKATA E SILVA, 2013) e seu principal objetivo é comunicar uma representação visual de um projeto ou ideia a ser utilizada em animações, filmes, quadrinhos ou games.

Segundo Nakata e Silva (2013), o concept art é a representação visual que busca a materialização de conceitos projetados para a indústria de entretenimento. Representa um auxílio visual de papel crucial no desenvolvimento de um projeto pois torna mais lógica a produção, viabilizando a incorporação, alteração e interação, visualmente, com as ideias propostas. A sistematização do processo criativo de personagens trata-se de um processo interativo de design, já que sua execução não depende de técnica ou nível de acabamento, possibilitando ao artista de concept liberdade para expressar todo seu potencial. Ainda conforme os autores, o desenho de conceito pode ser definido como um grupo de dicas visuais utilizadas para propor o entendimento da proposta pelo observador, abrangendo o design como um todo e suas qualidades visuais específicas. Ele solidifica um pensamento, partindo para um design mais apurado. É neste momento que um designer avalia as possibilidades futuras, buscando sanar as incertezas.

Através do design de personagens é possível aflorar expectativas, crenças e reações do público quanto aos aspectos formais, aparência e personalidade de um personagem. Cada personagem a ser criado possui uma acepção baseada em modelos já estabelecidos em lendas e mitos. O conjunto de personagens principais (heróis e vilãos) e secundários integram uma demasiada tradição narrativa que tem origem mítica e/ou religiosa (NAKATA E SILVA, 2013).

Conforme apontam Nakata e Silva (2013), atualmente, os personagens são bem projetados e elaborados, contribuindo para que haja uma mesma compreensão, independente da pessoa que o consuma. $O$ autor também realça que este público está mais refinado com relação ao visual dos personagens. Algo que agradava o público antigamente pode não ter o mesmo impacto com o público atual. Por fim, ele reforça que, em conjunto com esse poder de manipulação da imaginação alheia, obtém-se a responsabilidade de desenvolver personagens bem-sucedidos.

Em suma, o concept art é a representação visual do projeto ou ideia a ser utilizado nas midias, isso inclui os jogos eletrônicos. Este processo de criação pode ser considerado um conjunto de dicas visuais utilizadas para propor um design a um observador informado. Ele consolida um pensamento, transformando-o em um design apurado. É através do design de personagens que o designer consegue transmitir sua mensagem a seu público alvo através da aparência, roupas e personalidade dos personagens criados. Dependendo da mensagem enviada por esse designer ele pode tanto aproximar quanto afastar certo tipo de público, o que ocorre devido ao fato de que as pessoas atualmente conseguem ter a mesma compreensão de um projeto. Esse é um fato que pode 
estar acontecendo com alguns tipos de jogos eletrônicos, como os jogos de luta, por exemplo, que possui predominantemente maior público masculino. Muitas vezes o design dos personagens (principalmente das personagens femininas) desses jogos são pensados para agradar a esse público, deixando de lado o público feminino, que, por sua vez, respondem a isso não consumindo esses jogos. Claro que o design dos personagens não é o único fator que afasta esse público, mas pode ser um grande fator para que ocorra esse afastamento.

\section{A Mulher como Gamer}

Ainda que no imaginário comum o perfil do consumidor de jogos eletrônicos seja jovem e masculino, percebe-se uma tendência crescente da participação das mulheres notada, principalmente, nos fóruns e redes sociais específicos. A Pesquisa Game Brasil (2017), que traça o perfil do público consumidor dentro do país, corrobora com essa percepção: a maioria do público gamer brasileiro pertence ao sexo feminino, público que vem aumentando desde de 2013, ano que possuía um total de 41\% de jogadoras femininas. Em 2015 o Brasil possuía um total de 47,1\% de mulheres consumidoras de jogos eletrônicos, subindo para 52,6\% em 2016 e 53,6\% no ano de 2017.

Essa tendência também se repete em escala mundial. Conforme aponta a pesquisa realizada em 2014 pelo Internet Advertising Bureau, as mulheres representam 52\% dos gamers. Ou seja, ambas as pesquisas vão contra essa crença de que grande parte do público gamer é masculino.

Embora tenha crescido bastante, o público feminino ainda não tem muita visibilidade dentro da indústria de games, o que pode ser observado nos roteiros, personagens e publicidade direcionados para um público-alvo basicamente do gênero masculino. Isso acontece, porque a sociedade cria e institui valores acerca do que é para ser consumido por meninos e por meninas e normalmente é destinado às meninas brinquedos voltados para a construção social da mulher, que é cuidar do lar, ser delicada, gostar de moda. Assim, foram direcionados a esse público brinquedos como bonecas, artigos de beleza, minicozinhas, entre outros e não jogos eletrônicos (BRISTOT, FRIGO \& POZZEBON, 2017)

Apesar de a sociedade direcionar produtos às pessoas baseada em seu sexo biológico, a questão da definição do gênero de um indivíduo é algo muito mais complexo. Algumas pessoas acreditam que esteja ligado somente a diferenças biológicas, mas diversos estudos acerca de identidade de gênero dizem que os comportamentos masculinos e femininos estão mais ligados a criações culturais do que ao sexo biológico em si. São criados certos padrões comportamentais em que algumas práticas são definidas como sendo algo feminino ou masculino, desse modo o indivíduo faz a sua escolha conforme a sua identificação com determinados aspectos, postura, valores e condutas sociais, não sendo necessariamente a mesma de seu sexo biológico. Conforme citam Bristot, Frigo \& Pozzebon (2017, p.2).

Existem expectativas culturais de uma sociedade com relação a cada sexo. Antes mesmo do indivíduo nascer ao saber o sexo do bebê, os pais já definem seu gênero impondo a ele o que culturalmente é definido para aquele gênero como cores, gostos, atitudes e ideias que vão ser mantidos pela família, escola e sociedade.

Há uma segmentação de mercado que tende a separar e reforçar a ideia de que existem interesses distintos de acordo com o sexo. A segmentação de mercado tende a direcionar um público consumidor específico que apresente necessidades semelhantes como idade, comportamento, sexo, gênero, etc. 
Isso não é diferente com os games. Historicamente os videogames são vistos como uma atividade relacionada com o gênero masculino. Eles passaram por essa segmentação de gêneros no mercado durante os anos 80. A recessão que veio nessa época, fez com que o mercado se direcionasse ao público masculino que era apontado como a maioria consumidora, para evitar correr riscos e se recuperar. Desse modo, a sociedade criou o valor de que videogame era algo masculino (IZUKAWA, 2015).

Segundo Bristot, Frigo \& Pozzebon (2017), devido ao direcionamento dos jogos para o público masculino, a indústria tentou conquistar o público feminino com fórmulas estereotipadas, primeiro com a criação do próprio Pac-Man cujo único objetivo era comer e, posteriormente, com a criação de seu par romântico, Ms. Pac-Man, reforçando a preferência feminina por romances. Além disso, durante os anos 90 surgem os jogos voltados ao público gênero feminino, que traziam consigo atividades estereotipicamente femininas, reforçando ainda mais essa divisão entre gêneros dos games.

Além disso, o próprio desenvolvimento de games ainda é visto pela sociedade como uma atividade masculina. Mesmo tendo grandes exemplos femininos, como Carol Shaw, Roberta Williams, Amy Hennig e outras que foram citadas anteriormente, as mulheres ainda são menor número dentro da indústria de produção de games. Segundo a International Game Developers Association estima-se que atualmente apenas $22 \%$ dos funcionários de empresas de games são mulheres. No Brasil isso não é muito diferente, de acordo com pesquisa realizado no ano de 2013 pelo Grupo de Estudos e Desenvolvimento da Indústria de Games (GEDIGames), apenas 15\% dos trabalhadores dessas empresas são mulheres.

Ainda que sejam maioria dentro do público gamer, as mulheres continuam passando por muitos preconceitos dentro do mundo dos jogos. Elas têm que provar constantemente que os estereótipos empregados ao sexo feminino não são verdadeiros, que elas não são limitadas às escolhas e tipos de comportamentos ditos "de mulher". Além disso, não há uma representatividade feminina nos games. Isso se deve ao fato dos estereótipos em que as mulheres são representadas pela figura da donzela frágil, dócil, que precisa ser salva pelo seu herói e/ou através da figura da mulher hipersexualizada (BRISTOT, FRIGO \& POZZEBON, 2017).

Muitas dessas mulheres que adentram o mundo dos games expõem que sofrem algum tipo de reação negativa a sua presença. Há diversos relatos de mulheres que são xingadas em redes sociais, questionadas a respeito sobre sua aparência e formação para falar sobre games. Essas mulheres também dizem sofrer assédio nos jogos em que têm que jogar com mais pessoas, tendo que utilizar nomes e avatares masculinos para evitar esse tipo de situação. Além disso, existe casos em que o preconceito chega ao nível extremo de jogadores do sexo masculino ameaçarem de estupro ou morte mulheres que ousem se impor nesse meio. Em 2012, com a youtuber feminista Anita Sarkeesian recebeu ameaças e teve suas informações pessoais vazadas na internet por fazer vídeos onde criticava exatamente a questão da representação e objetificação de personagens do sexo feminino (OLIVEIRA, 2017). Mas, mesmo sofrendo tanto preconceito, essas mulheres resistem a eles, jogando diferentes gêneros de games e criando conteúdo a respeito deles. Hoje é comum ver mais mulheres se interessando pela área da criação de games, de personagem para games, criando conteúdos em blogs e até mesmo no próprio YouTube. 
No Brasil existem os blogs Garotas Nerds ${ }^{2}$, Garotas Geeks ${ }^{3}$ e Minas Nerds ${ }^{4}$, que são feitos somente por mulheres que, apesar de não tratarem apenas de games, trazem conteúdos como notícias, reviews, entre outras coisas sobre games que até pouco tempo atrás eram feitos somente por homens. Além desses blogs, no YouTube existem diversos canais feitos por mulheres sobre games. Um bom exemplo disso é o canal americano feministfrequency ${ }^{5}$, criado pela já citada canadense Anita Sarkeesian, que trata a questão da representatividade feminina nos games em seus vídeos.

Apesar de ter quem se sinta ameaçado pela presença feminina no universo dos games, têlas inseridas nesse meio é algo positivo, pois ajuda a aumentar o número de jogadores, fazendo com que o mercado se torne mais dinâmico e inovador.

\section{Mulheres nos Games}

\subsection{Representatividade Feminina}

Representar significa dizer em nome de um grupo ou parcela da população. Tão em voga nos últimos anos, o termo representatividade tem sido muito utilizado no tocante a dar voz às minorias ou os excluídos, sejam numericamente como socialmente. Nesse atual contexto são contemplados os negros, as mulheres, os homossexuais, as pessoas com deficiência entre outros, de forma que os estereótipos negativos sejam diminuídos. Apesar de estar presente nos games, a figura da mulher não representa a diversidade feminina que realmente existe. Isso é visível tanto no comportamento quanto na aparência física das personagens. Muitas vezes a mulher é representada com corpos, muitas vezes, irreais anatomicamente, com seios volumosos e curvas acentuadas. Seus figurinos constituem, de maneira geral, em pouca vestimenta que não condizem com a situação em que a personagem está inserida, como o caso das personagens femininas utilizando salto em batalhas nos torneios de luta. Além disso, as mulheres possuem papéis secundários, servindo como suporte ao desenvolvimento do personagem masculino ou de sua história. Mesmo quando são protagonistas dos jogos, elas acabam sendo estereotipadas de forma a agradar o olhar masculino, e não a realmente representar a mulher (BRISTOT, FRIGO \& POZZEBON, 2017).

$O$ fato de as personagens femininas serem representadas de forma estereotipada pode estar relacionado com o fato de grande parte dos desenvolvedores de games serem do sexo masculino. Por desenvolverem os jogos e personagens esses homens podem empregar suas perspectivas neles.

\subsection{Objetificação da Mulher}

Segundo Bristot, Frigo \& Pozzebon (2017), objetificação se refere à banalização da imagem da mulher, tornando a aparência algo mais relevante que as características que a identifica como sujeito, transformando-a em objeto.

Existem algumas características que podem ajudar a identificar a objetificação da mulher nos games. São elas: 1) a instrumentalidade, característica de personagens que são um instrumento a ser utilizado por outro personagem, agindo somente na presença deste; 2 ) a mercantilização, onde a personagem é apenas um objeto e tem como única função ser moeda de troca ou mercadoria a ser vendida; 3 ) a permutabilidade, que ocorre quando uma personagem pode ser trocada por outra

\footnotetext{
${ }^{2}$ http://garotasnerds.com/

${ }^{3}$ http://www.garotasgeeks.com/

${ }^{4}$ http://minasnerds.com.br/

${ }^{5}$ https://www.youtube.com/user/feministfrequency
} 
personagem ou objeto sem que se tenha qualquer alteração na narrativa da história; 4) a violabilidade, que aparece em games que permitem que a personagem seja violada e abusada sexualmente, sendo, algumas vezes, essa atitude uma recompensa para o jogador que cumpriu o que o jogo propunha; e 5) a descartabilidade, que ocorre quando uma personagem é descartada sem que se altere qualquer coisa na narrativa do jogo, estando lá somente para agradar os desejos dos jogadores (IZUKAWA, 2015).

Outra forma utilizada pelos produtores dos jogos para sexualizar suas personagens é utilizando algumas técnicas que evidenciam a sensualidade dela. Uma forma de fazer isso é através do movimento das personagens, com movimento exagerado, e muitas vezes não naturais, de seus seios, sua forma de andar com rebolados exagerados, que não condizem com a situação em que ela está inserida. Esses movimentos podem fazer sobressair a sensualidade, se tornando algo tão apelativo que acaba por hipersexualizar a personagem. Isso também acontece em momentos que a câmera não é controlada pelo jogador e na chamada cutscene, cuja proposta é interromper a jogabilidade e trazer ao jogador informações, introduzir novos personagens ou, até mesmo, reforçar o desenvolvimento do protagonista. Nessa situação a câmera, geralmente, é pensada de forma a mostrar o corpo da personagem a hipersexualizando. Além de tudo isso, as roupas são mais uma forma de sexualizar e objetificar a personagem, pois é através dela que é passada a primeira impressão acerca da postura e personalidade da mesma. Essas roupas são, comumente, impróprias para as situações em que as personagens se encontram, sendo pensadas para trabalhar sua sensualidade e agradar ao público masculino. Elas costumam ser coladas, de forma que as curvas do corpo se destaquem e a sensualidade sobreponha a personalidade da personagem, que também costuma ser estereotipada. As personagens acabam possuindo uma personalidade unidimensional, que pode apresentar traços de futilidade, mau humor, excesso de carinho ou irritação por qualquer coisa (BRISTOT, FRIGO \& POZZEBON, 2017).

Apesar de já existirem jogos de grande sucesso comercial com protagonistas femininas, como Metroid e Tomb Raider, suas personagens ainda carregavam diversos esteriótipos adversos ao conceito de representatividade. Segundo citam Bristot, Frigo \& Pozzebon (2017), em Metroid o jogador só ficava sabendo que Samus Aran era uma mulher ao final do jogo, isso se ele o terminasse com uma pontuação, no mínimo, razoável. Sua identidade somente era revelada como um prêmio ao jogador que se esforçasse para terminar o jogo bem. Caso o jogador terminasse o jogo com mais de 5 horas, nem ficava sabendo que a protagonista era uma mulher. Já se ele finalizasse em torno de 3 a 5 horas, a armadura da personagem piscava e o capacete era retirado revelando seu rosto. Caso o jogo fosse finalizado em menos de 3 horas, a armadura era retirada e a personagem ficava somente com um collant rosa. Se o jogador vencesse o jogo em menos de uma hora Samus ficava sem sua armadura, usando somente com um biquíni rosa.

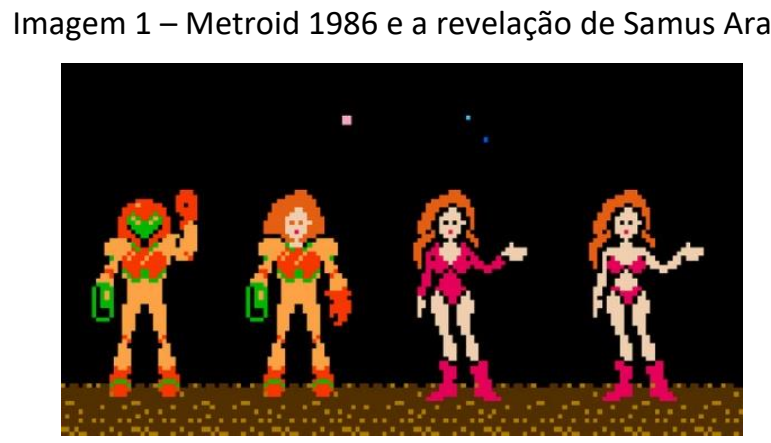


Já Tomb Raider apresenta uma protagonista que possui tudo para ser um grande exemplo de representatividade feminina nos games. Lara Croft é uma personagem inteligente, forte e destemida, mas era vista como símbolo sexual, vestida com mini shorts, blusas coladas e decotes, suas roupas não condiziam com a situação em que estava inserida. Além disso, a câmera do jogo ficava focada de forma que as nádegas da personagem estivessem no centro de seu foco. Isso tudo acabou por levantar o questionamento do quanto ela estava no jogo para ser uma realmente uma representação feminina ou apenas um objeto de desejo para o público masculino. Para corrigir essa questão da hipersexualização da personagem e algumas pontas soltas em sua história, em 2013 seus produtores resolveram refazer a série do zero, onde foi apresentada uma Lara mais jovem, com roupas mais funcionais e mais adequadas às situações enfrentadas por ela, além de proporções realistas em seu corpo (NARCISO, 2014).

Com a questão acerca da representatividade feminina sendo cada vez mais abordada, muitos jogos estão repensando suas personagens, como aconteceu com Tomb Raider, e começam a surgir games em que a protagonista se torna, de fato, central na trama. No evento anual de jogos Electronic Entertainment Expo (E3) de 2016 foram anunciados cinco grandes jogos com protagonistas femininas. Entre esses jogos estão os aclamados Gears of War e Mass Effect. Esse número pode parecer pequeno perto da quantidade de jogos que são lançados, mas são um avanço em um universo que ainda é predominantemente voltado ao masculino e em que até pouco tempo atrás se utilizava a imagem da mulher apenas para agradar a esse público. Esses avanços mostram que cada vez mais as mulheres estão conseguindo se impor e conquistar seu espaço nesse universo ${ }^{6}$.

\section{A Mulher no Jogo Street Fighter V}

\subsection{Os Jogos de Luta}

O jogo de luta é um gênero de jogos de videogame que tem como característica o combate direto entre os oponentes que estão em tela. Para as lutas, o jogador escolhe um dos personagens disponíveis e enfrenta seu adversário em diversos rounds que ocorrem em arenas presentes nos jogos. O primeiro jogo desse gênero foi o Knights in Armor, lançado pela Sega em 1976. Mas os jogos de luta como são conhecidos hoje surgiram a partir do famoso Street Fighter, que teve sua primeira versão lançada em 1987 pela produtora de jogos Capcom. Este foi o primeiro jogo de luta a apresentar uma história mais detalhada. Nele, o lutador Ryu viaja o mundo para provar sua força. O jogo não obteve tanto sucesso, mas revolucionou o mundo dos games apresentando diversas mudanças aos jogos de luta. Os controles do jogo eram inovadores, pois utilizava um sistema de seis botões para executar os comandos dos personagens. Além disso, a Capcom se preocupou em escrever uma história de fundo para cada um dos personagens presentes no game, adicionou golpes especiais a eles e cenários de fundo para cada batalha. Apesar de tudo isso, o jogo não obteve muito sucesso. Ainda assim seus criadores resolveram lançar uma continuação para o game, assim Street Fighter II foi lançado em 1991 e conquistou de imediato o mercado, sendo considerado um dos melhores jogos de luta até hoje (MCLAUGHLIN, 2009).

Foi somente a partir deste jogo que o jogador passou a ter a possibilidade de escolher com qual personagem ele iria jogar, conforme cita McLaughlin (2009). No primeiro jogo ele só tinha a

\footnotetext{
${ }^{6}$ https://jogos.uol.com.br/listas/mulheres-em-alta-5-jogos-da-e3-com-protagonistas-femininas.htm
} 
opção de jogar com o protagonista Ryu ou com sua versão de quimono vermelho e cabelo loiro, que mais tarde viria se tornar seu melhor amigo Ken. É nesta versão também que o jogo apresenta sua primeira personagem feminina, a chinesa Chun-Li, que além de ser a primeira era também a única mulher no jogo. Com sua fórmula de sucesso a franquia conquistou muitos fãs com o passar dos anos e o jogo teve algumas continuações. O mais recente jogo da franquia é o Street Fighter $V$, lançado em 2016. E, assim como suas versões aumentaram, a quantidade de personagens também cresceu e mais personagens mulheres foram adicionadas à franquia.

O sucesso da franquia Street Fighter abriu caminho para o surgimento de novos jogos de luta posteriormente, incluindo os sucessos Fatal Fury e Mortal Kombat. Percebendo esse sucesso a Sega resolve se aventurar lançando o primeiro jogo de luta com gráficos 3D, o Virtua Fighter, mas o mesmo só obteve sucesso por um breve período, pois seus controles eram básicos demais e qualquer um poderia chegar e jogar. Apesar disso, o jogo abriu as portas para que mais jogos nesse estilo fossem lançados e, em 1994, surge nos arcades japoneses a franquia de jogos de luta 3D Tekken, lançado pela produtora Namco. Além de inovar trazendo gráficos 3D, o jogo apresentou personagens de diversos países do mundo que decidem, por motivos diversos, participar do torneio King of the Iron Fist Tournament. Todos possuíam uma narrativa de fundo própria e um estilo de luta que existe no mundo real, como a capoeira, o caratê e o tae kwon do. O jogo é considerado hoje um dos maiores jogos de luta, concorrendo diretamente com o Street Fighter.

Mesmo com essas inovações, o sucesso dos jogos de luta diminuiu no final dos anos 90 . Foi apenas no começo dos anos 2000 que os jogos de luta reconquistaram seu sucesso. Isso ocorreu com o lançamento do sucesso da Nintendo, Super Smash Bros. e sua sequência Melee. Foi também nesse período que surgiram o famoso torneio de jogos de luta Evolution Championship Series (EVO) nos EUA. São disponibilizados alguns jogos no torneio e os fãs se inscrevem em um jogo escolhido por eles mesmos para participar e concorrer ao prêmio máximo da competição. Existe inclusive empresas especializadas em peças e acessórios tecnológicos que patrocinam os melhores competidores. É como se fosse as olimpíadas dos jogos de luta (GILYADOV, 2015).

No cenário atual do mundo gamer os jogos de luta continuam fazendo sucesso e o campeonato EVO cresceu com o passar dos anos, aumentando sua lista de jogos e competidores participantes. Seus jogos de maior sucesso são o Super Smash Bros. Melee, Tekken e o Street Fighter, que é o carro chefe da competição. Apesar de ter atingido um grande sucesso e ter competidores do mundo inteiro participando dele, ainda é raro ver uma mulher competindo no torneio. Na lista ${ }^{7}$ dos oito melhores colocados nos nove jogos presentes no EVO 2017 não existe sequer uma mulher presente. Todos os competidores são homens. Isso se deve, provavelmente, ao fato de esse cenário do mundo dos games ser muito masculino ainda. Mulheres que se aventuram pelos jogos de luta sofrem com preconceito disseminado pelos jogadores masculinos. Um exemplo disso é o caso da jogadora Cristina Santos, que em 2013 conquistou o primeiro lugar no ranking mundial do jogo "Super Street Fighter IV: Arcade Edition" e por isso foi alvo de ataques por parte dos jogadores do sexo masculino em suas redes sociais e, até mesmo, em sua vida pessoal (BERNARDO, 2017). Além disso, o fato de as mulheres não se interessarem tanto pelos jogos de luta pode também estar ligado ao fato de elas não terem representatividade dentro dos jogos. Nas franquias de jogos de luta existem sim personagens mulheres, entretanto elas não representam realmente a mulher. A grande maioria está lá para agradar aos olhos dos jogadores masculinos. Elas costumam ser representadas

\footnotetext{
${ }^{7}$ http://shoryuken.com/2017/07/16/evo-2017-championship-series-results/
} 
de forma hipersexualizada e não costumam ter importância dentro da história principal do jogo.

\subsection{Representatividade Feminina no Jogo Street Fighter V}

A franquia Street Fighter é conhecida até hoje por ser uma das maiores dentro dos jogos de luta. O game possui uma grande base de fãs fiéis e é a atração principal do campeonato EVO, sendo responsável por encerrá-lo com suas finais. Apesar disso, o número de mulheres que competem no torneio é muito baixo. Ao consultar a lista dos oito finalistas do torneio em 2017 não se encontra uma mulher se quer. Isso pode ser reflexo do fato de os jogos de luta serem classificados como sendo algo masculino e de o jogo buscar agradar aos jogadores do sexo masculino que ainda é o público que o consome, evitando riscos. Apesar de não se ter nada concreto que demonstre o porquê de as mulheres não consumirem esse tipo de jogo, isso pode estar ligado ao fato de elas não se sentirem representadas dentro do jogo.

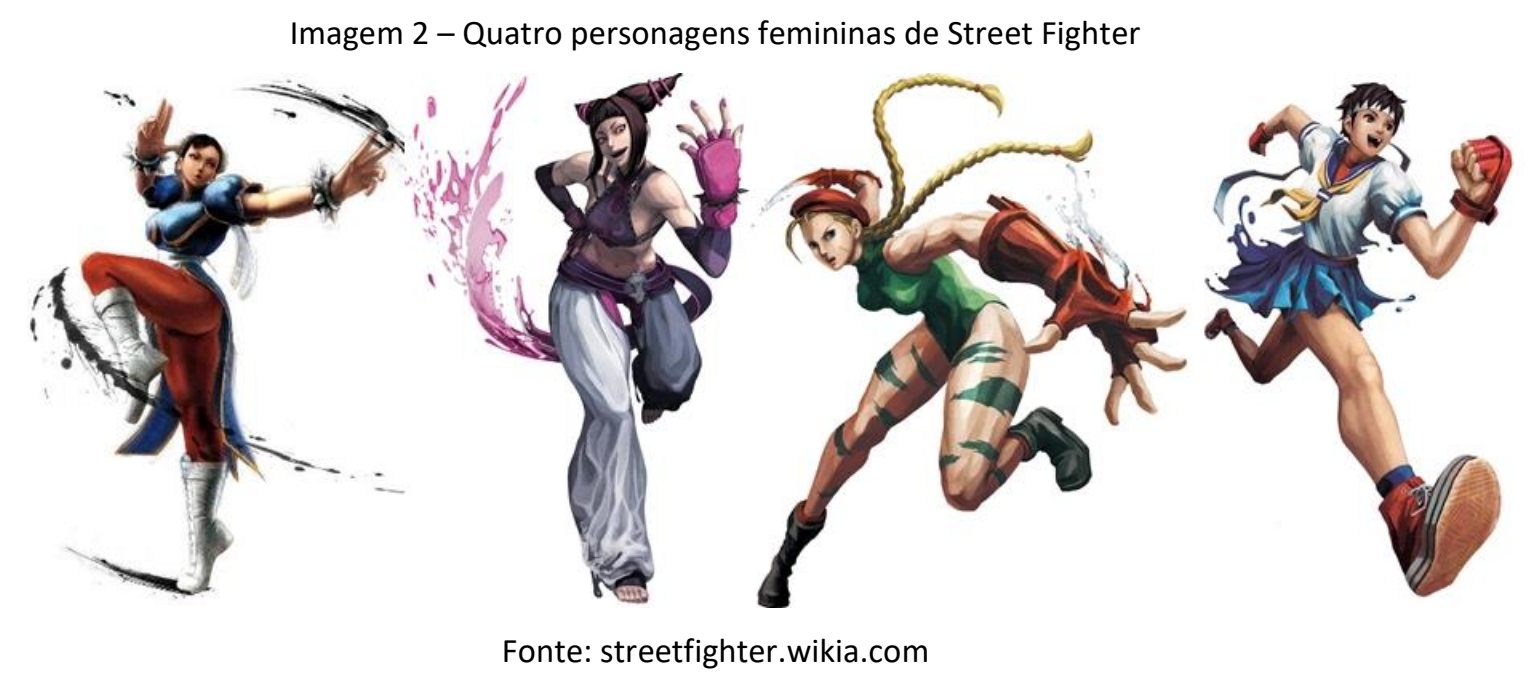

O novo jogo da franquia, o Street Fighter $V$, possui até o momento 30 personagens, sendo 10 deles do sexo feminino. Entretanto, nenhuma dessas personagens femininas representa realmente a mulher em sua diversidade. Todas elas, mesmo tendo idades diferentes, sendo de países diferentes, possuem o mesmo tipo físico. Todas têm o corpo hipersexualizados, com curvas exageradas, seios fartos e coxas grossas. Normalmente com roupas que não condizem com a situação em que estão inseridas, que no caso seriam batalhas de artes marciais. Há quem defenda essa hispersexualização alegando que todos os personagens do jogo são estereotipados, que isso é uma característica de Street Fighter. Entretanto, nos personagens homens existem diversos tipos de estereótipos. É possível se encontrar personagens musculosos, gordos, magros, altos e baixos, enquanto que as mulheres têm sempre o mesmo molde de corpos.

Entre todas as personagens do jogo a brasileira Laura Matsuda foi protagonista de um grande debate logo após o anúncio de sua roupa alternativa. No jogo, Laura é uma brasileira descendente de japoneses que foi treinada no estilo Matsuda de jiu jitsu. Ela se torna herdeira do estilo de arte marcial de seu dojo e decide sair pelo mundo para divulga-lo, se envolvendo em batalhas com diversos dos personagens da franquia. 


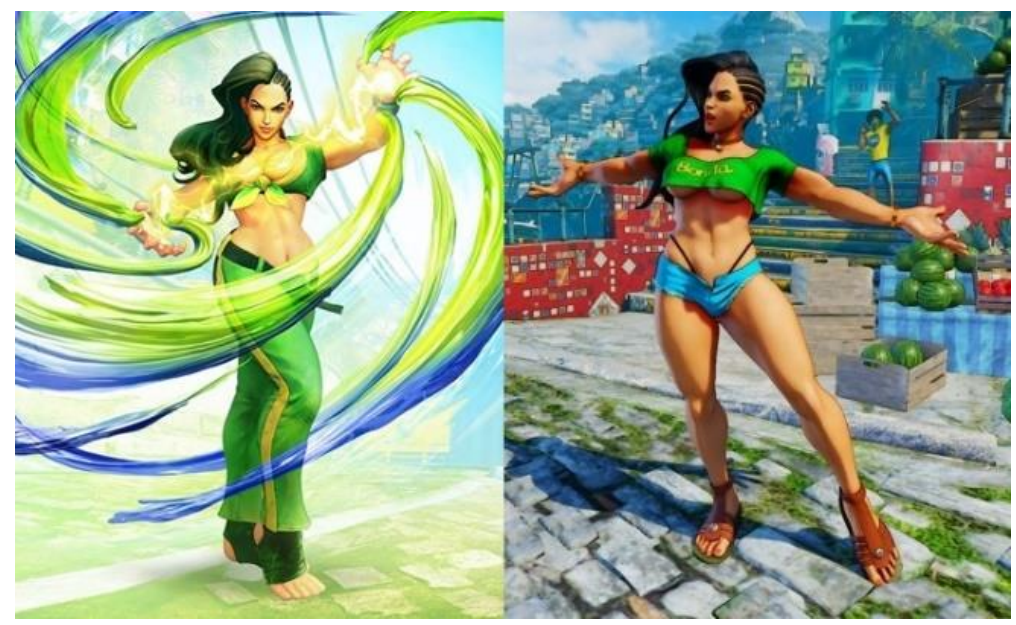

Fonte: sfv.wikia.com e atomix.vg

Em sua versão de roupa padrão Laura aparece usando um top e calça verde e amarelo. Já em sua versão alternativa, ela aparece usando um top que mal cobre seus seios, short curto que mostra a roupa íntima da personagem e sandálias. Devido a isso muito se foi discutido a respeito do quanto a personagem realmente representava uma lutadora brasileira e o quanto ela estava lá para somente satisfazer os desejos sexuais do público masculino. Para se defender dos questionamentos a produtora Capcom se pronunciou dizendo que também há muitos personagens masculinos em Street Fighter $V$ com os corpos bastante a mostra. Entretanto, a questão da sexualização da personagem vai muito além da quantidade de pele que é mostrada, primeiro porque apesar de ter sim personagens masculinos com roupas que mostram partes de seus corpos no jogo isso não ocorre com todos que estão presentes, além de que suas roupas não foram pensadas de forma a sexualizar o personagem. O próprio personagem Zangief é um dos que aparecem com pouca roupa, mas isso é usado para evidenciar seus músculos e sua força e não para servir como um atrativo sexual ao público consumidor.

Outra justificativa usada pela Capcom foi a que para criar um personagem eles consultam parceiros para que não haja desrespeito com nenhuma das culturas retratadas por eles. Claro que é normal encontrar mulheres com roupas curtas no calor extremo do Rio de Janeiro, entretanto nenhuma delas se envolve em batalhas para divulgar seu estilo de luta com essas roupas. Além disso, mesmo a roupa padrão de Laura possui problemas, afinal ela é uma poderosa lutadora de jiu jitsu que tem por objetivo divulgar seu dojo, por isso ela deveria estar usando um quimono em suas batalhas, assim como ocorre com os personagens Ryu e Ken. Ao se pensar em seu objetivo, no ambiente em que ela está inserida e nos golpes que ela teria que desferir em uma batalha tanto sua roupa padrão quanto a alternativa a atrapalhariam durante uma luta, pois não são próprias para isso e dificultariam os movimentos de seus golpes.

Imagem 4 - Cenas da pose de entrada de Laura Matsuda

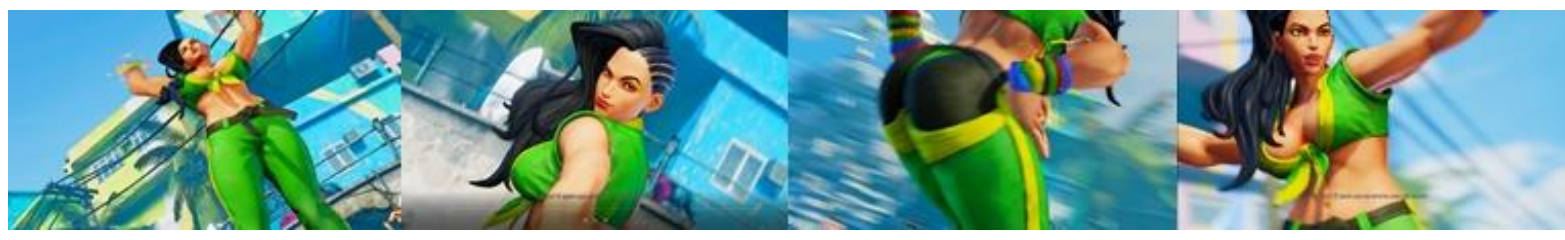


Suas roupas poderiam ser justificadas por conta do estilo e personalidade que os produtores queiram que ela demonstre, entretanto, a hipersexualização da personagem Laura não é feita somente por meio delas. Ela poderia utilizar roupas mais curtas e não ter o apelo sexual que possui, pois isso não é criado somente através da roupa que a personagem está usando. Até mesmo uma personagem com uma roupa que não mostre alguma parte de seu corpo pode ser hipersexualizada por meio de seus gestos e expressões e isso também ocorre com Laura. O jeito como ela se mexe e as expressões em seu rosto durante suas poses de entrada e vitórias nas batalhas são feitos de forma a evidenciar sua sensualidade. Além disso, a câmera do jogo sempre é utilizada de forma a evidenciar as curvas surreais de seu corpo. Tanto na pose de entrada quanto de vitória a câmera passa por todo o corpo da personagem sempre focando seus glúteos e seios. Isso demonstra que o foco do jogo é evidenciar o corpo da personagem e não sua personalidade e estilo. E isso não é exclusivo de Laura, com todas as personagens femininas do game ocorre esse jogo de câmera em suas poses de entrada, vitória e ataque especial. Os produtores do jogo, inclusive, tiveram problemas com esse jogo de câmera no golpe especial da personagem Rainbow Mika e acabaram por retirar uma cena em que a personagem aparece dando um tapa em umas de suas nádegas logo no início de sua animação. Embora essa cena tenha sido retirada, isso não aconteceu porque poderia incomodar possíveis jogadoras do sexo feminino, mas para evitar que algum órgão de classificação indicativa não aprovasse jogo e a produtora não conseguisse atingir seu público alvo, que engloba adolescentes e adultos.

Imagem 5 - Cena retirada do especial de R. Mika

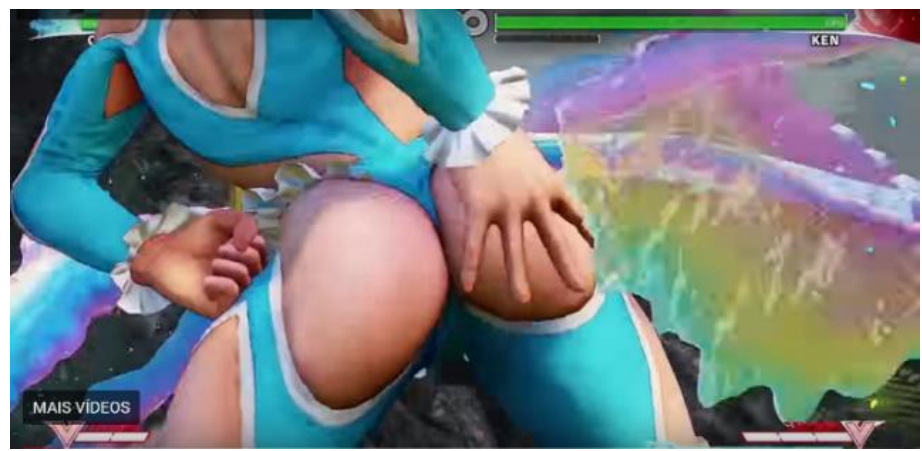

Fonte: Street Fighter V

A conclusão que se chega ao ver como a Capcom representa suas mulheres é que apesar de contar com grande quantidade de personagens femininas, ela não demonstra preocupação em trabalhar para que essas personagens tenham uma participação mais significativa dentro do jogo, utilizando o design de suas personagens somente para agradar e atrair seu público foco, que são homens adolescentes e adultos. Como aponta Nakata e Silva (2013), atualmente as percepções de cada indivíduo integrante do público consumidor de games estão mais próximas umas das outras e isso pode ser um pode ser um dos fatores que afasta o público feminino do game, pois, muitas mulheres não se sentiriam representada pelas personagens do jogo, já que todas têm o mesmo padrão de corpo e roupas hipersexualizadas, o que não engloba a real diversidade feminina existente no mundo real. Ou seja, esse design de personagem, que funciona bem para o público masculino, pode não funcionar para o feminino, pois, ambos conseguem captar a mesma mensagem enviada pelo designer criador dos personagens em questão e essa mensagem pode ser algo que agrada um, mas desagrada o outro. Talvez se esses designers de personagens da Capcom 
repensassem suas personagens, tendo como foco a representatividade feminina, assim como os produtores de Tomb Raider fizeram, o jogo Street Fighter $V$ conseguiria um público consumidor maior do que já possui atualmente.

\section{Considerações Finais}

Ainda que estejam presentes na indústria de videogames há anos, as mulheres ainda são minorias dentro desse universo, que é visto como sendo masculino, e enfrentam muito preconceito por parte de jogadores do sexo masculino que se sentem incomodados com sua presença. Apesar de toda a dificuldade, elas lutam para se impor e já são o maior público consumidor de games na atualidade. Isso abriu os olhos de algumas produtoras de jogos eletrônicos, como Tomb Raider, que modificaram suas protagonistas de forma a representar realmente a mulher e não de servir como um agrado aos olhos do público masculino.

Indo na contramão dessa tendência estão os jogos de luta. O game Street Fighter continua sendo um dos mais bem-sucedidos jogos de luta, possuindo uma base de fãs fiéis e sendo a principal atração do torneio profissional de jogos de luta, EVO. Entretanto, ainda é raro se encontrar mulheres jogando o jogo profissionalmente. Isso pode ter relação com o fato de elas não se sentirem representadas pelo jogo, visto que esse possui bastante personagens femininas, mas o design de nenhuma delas representa realmente a diversidade feminina existente. Mudar esse fator do jogo pode fazer com que o público feminino, que é maioria na atualidade, se interesse mais por ele e passe a consumi-lo também, aumentando suas vendas e fazendo com que ele fique mais dinâmico, com personagens cujo design realmente difere umas das outras.

\section{Referências Bibliográficas}

AMOROSO, Danilo. A história dos videogames: do osciloscópio aos gráficos 3d, 2009. Disponível em: <https://www.tecmundo.com.br/xbox-360/3236-a-historia-dos-video-games-do-osciloscopio-aosgraficos-3d.htm>. Acesso em: 18 mar. 2018.

BERNARDO, André. Maioria entre gamers no brasil, mulheres enfrentam preconceito e assédio, 2017. Disponível em: < http://www.bbc.com/portuguese/brasil-39287008/>. Acesso em: 24 mar. 2018.

BRISTOT, Paula Casagrande; FRIGO, Luciana Bolan; POZZEBON, Eliane. A representatividade das mulheres nos games. XVI SBGames, Curitiba - PR - Brasil, nov. 2017.

GNIPPER, Patricia. Mulheres históricas: carol shaw, a primeira desenvolvedora de jogos eletrônicos, 2016. Disponível em: <https://canaltech.com.br/internet/mulheres-historicas-carol-shaw-aprimeira-desenvolvedora-de-jogos-eletronicos-75877/>. Acesso em: 18 mar. 2018.

GILYADOV, Aleksander. Ko: the history of fighting games, 2015. Disponível em: <https://www.cgmagonline.com/2015/04/15/ko-the-history-of-fighting-games/>. Acesso em: 26 mar. 2018.

GUTIERREZ, Barbara. Street fighter v | a hipersexualização de laura é justificável?, 2016. Disponível em: $\quad<$ https://www.theenemy.com.br/street-fighter-v/street-fighter-v-a-hisperssexualizacao-delaura-e-justificavel>. Acesso em: 29 mar. 2018.

GUTIERREZ, Barbara; GASI, Flávia. Conheça 13 mulheres que são essenciais na indústria dos jogos, 2018. Disponível em: <http://br.ign.com/brasil/18442/news/conheca-13-mulheres-que-sao- 
essenciais-na-industria-dos-jogo>. Acesso em: 24 mar. 2018.

IZUKAWA, Mariana. Mulher entre espelhos - personagens femininas customizáveis nos videogames. TCC (Graduação) - Curso de Graduação em Design, Faculdade de Arquitetura e Urbanismo, Universidade de São Paulo, 124p, São Paulo, 2015.

MCLAUGHLIN, Rus. Ign presents the history of street fighter, 2009. Disponível em: <http://www.ign.com/articles/2009/02/16/ign-presents-the-history-of-street-

fighter?page=1>. Acesso em: 25 mar. 2018.

NAKATA, Milton Koji; SILVA, Jose Carlos Placido Da. Concept art para design: criação visual de objetos e personagens. 1 ed. Bauru, SP: Canal 6, 2013. 160 p.

NARCISO, Eduardo. Personagens femininas que revolucionaram o mundo dos games, 2014. Disponível em: <http://www.afronte.com.br/personagens-femininas-que-revolucionaram-omundo-dos-games/>. Acesso em: 24 mar. 2018.

NEWZOO. 2017 global games market report. Disponível em: <https://resources.newzoo.com/hubfs/reports/newzoo_global_games_market_report_2017_light .pdf?t=1521801541670>. Acesso em: 10 mar. 2018.

OLHAR DIGITAL. História do Atari 2600. Disponível em: <https://olhardigital.com.br/games-econsoles/video/historia-do-atari-2600/32521>. Acesso em: 18 mar. 2018.

OLIVEIRA, Anny. Acesso negado: a indústria de games é uma indústria de homens, 2017. Disponível em: $\quad$ <http://jornalismojunior.com.br/sala33/acesso-negado-a-industria-de-games-e-umaindustria-de-homens/>. Acesso em: 24 mar. 2018.

PESQUISA GAME BRASIL 2017. Disponível em: <http://pesquisagamebrasil.com.br> Acesso em: 28 jan. 2018.

PESSOA, Breno. Público feminino enfrenta machismo na indústria gamer, 2016. Disponível em:<http://www.diariodepernambuco.com.br/app/noticia/viver/2016/11/17/internas_viver,6755 44/publico-feminino-enfrenta-machismo-na-industria-gamer.shtml>. Acesso em: 24 mar. 2018.

PISSETTI, Cínthia Provesi. Jogos e gênero - Pesquisa sobre uso, hábitos e práticas de mulheres jogadoras de vídeogames. TCC (Graduação) - Curso de Graduação em Tecnologias da Informação e Comunicação, Centro Tecnológico da Universidade Federal de Santa Catarina, Universidade Federal de Santa Catarina, 71p, Araranguá, 2017.

SHORYUKEN. Evo 2017 final results. Disponível em: <http://shoryuken.com/2017/07/16/evo-2017championship-series-results/>. Acesso em: 29 mar. 2018.

SOUZA, Alessandra; CAMURUGY, Laiza; ALVES, Lynn. Games e Gênero: A Emergência dos Personagens Femininos. Universidade do Estado da Bahia - Departamento de Educação, Brasil. VIII Brazilian Symposium on Games and Digital Entertainment, Rio de Janeiro RJ, 2009.

UOL JOGOS. Mulheres em alta: 5 jogos da e3 com protagonistas femininas, 2016. Disponível em: <https://jogos.uol.com.br/listas/mulheres-em-alta-5-jogos-da-e3-com-protagonistasfemininas.htm>. Acesso em: 24 mar. 2018.

ZAMBARDA, Pedro. Quais são os primórdios da indústria de games no brasil?, 2017. Disponível em: $<$ https://www.huffpostbrasil.com/pedro-zambarda/quais-sao-os-primordios-da-industria-degames-no-brasil_a_21668876/>. Acesso em: 23 mar. 2018. 
